\section{(- OPEN ACCESS}

\title{
Second-generation surveillance for HIVIAIDS in Pakistan: results from the 4th round of Integrated Behavior and Biological Survey 2011-2012
}

\author{
Faran Emmanuel, ${ }^{1}$ Momina Salim, ${ }^{2}$ Naeem Akhtar, ${ }^{3}$ Salwa Arshad, ${ }_{1}^{4}$ Tahira Ezra Reza
}

\begin{abstract}
Urdu and Arabic Abstract translations

${ }^{1}$ Centre for Global Public Health, University of Manitoba, Winnipeg, Manitoba, Canada ${ }^{2}$ Centre for Global Public Health, National AIDS Control Program, National Institute of Health, Islamabad, Pakistan ${ }^{3}$ National AIDS Control Program, National Institute of Health, Islamabad, Pakistan ${ }^{4}$ Centre for Global Public Health, Punjab AIDS Control Program, Lahore, Pakistan
\end{abstract}

\section{Correspondence to} Dr Faran Emmanuel, Centre for Global Public Health, University of Manitoba, Community Health Sciences, R070 Med Rehab Bldg 771, McDermot Avenue, Winnipeg, Manitoba, Canada R3E 0T6;

faran@cc.umanitoba.ca

Received 8 April 2013 Revised 25 June 2013 Accepted 8 July 2013 Published Online First 2 August 2013

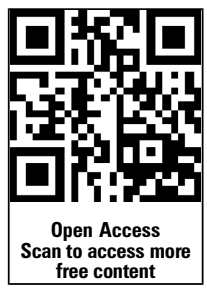

\footnotetext{
To cite: Emmanuel $F$, Salim M, Akhtar N, et al. Sex Transm Infect 2013;89: iii23-iii28.
}

\begin{abstract}
Objectives In an effort to fully analyse and understand the HIV situation and its epidemiology in Pakistan, a bilateral collaboration between the National AIDS Control Program and the Canadian International Development Agency resulted in the establishment of an effective second-generation surveillance (SGS) system for HIVIAIDS between 2004 and 2012 in accordance with the published guidelines. This paper presents findings from the 4th round of SGS.

Methods A mapping exercise was initially conducted for size estimations of the key vulnerable populations: people who inject drugs (PWIDs), male sex workers (MSWs), hijra sex workers (HSWs), and female sex workers (FSWs), followed by an Integrated Behavioral and Biological Surveillance in 20 selected cities across Pakistan.
\end{abstract}

Results The estimated sizes of the four key populations mapped in the 20 cities were 89178 FSWs, 46351 PWIDs, 23317 HSWs and 19119 MSWs. The HIV sero-prevalence among PWIDs was the highest among all key populations surveyed at $37.8 \%$ (Cl 37.3 to 38.3 ) nationally, followed by a prevalence of $7.2 \%(\mathrm{Cl} 6.8$ to 7.5) among HSWs, $3.1 \%(\mathrm{Cl} 2.8$ to 3.4$)$ among MSWs and $0.8 \%(\mathrm{Cl} 0.4$ to 1.0$)$ for FSWs. Various key risk behaviours, that is, sharing of syringes by PWIDs and inconsistent use of condoms by sex workers, were documented.

Conclusions Pakistan's HIV epidemic that once was characterised primarily by transmission among PWIDs is now increasingly characterised by significant sexual transmission, and all types of sex workers (male, hijra and female) exhibit epidemiological proportions of infection. There is a need to develop concrete strategic plans for each vulnerable subpopulation, initially focusing prevention resources on those with a higher risk or vulnerability.

\section{INTRODUCTION}

In response to the HIV pandemic, more countries are focused on developing systems to collect information about HIV trends to monitor their epidemics and to gather information to improve prevention planning and evaluation. ${ }^{1}{ }^{2}$ While differences in the epidemiology of and responses to HIV epidemics exist between and within countries, most countries in Asia, Europe and the Americas largely focus on people who inject drugs (PWIDs), female sex workers (FSWs), and men who have sex with men to understand their epidemics. ${ }^{3}$ Having an accurate picture of the HIV epidemiology and barriers to services is critical for countries to most effectively and efficiently allocate scarce HIV resources. ${ }^{4}$ To this end, Pakistan developed a second-generation surveillance (SGS) system to obtain extensive data about the status, changing trends and progress of its HIV epidemic. Unlike conventional surveillance systems, SGS helps identify vulnerability to infection and also ascertains the main determinants of the HIV epidemic. It also provides basic information for focusing and designing interventions, and for monitoring the impact of interventions proposed within the strategic planning process. ${ }^{5-7}$

Between 2004 and 2012, a bilateral collaboration between the National AIDS Control Program and the Canadian International Development Agency resulted in the establishment of an effective national SGS system for HIV/AIDS through the Canada-Pakistan HIV/AIDS Surveillance Project. This was implemented by a consortium of Agriteam Canada Consulting, University of Manitoba, Canada and ProAction: Partners for Community Health Inc, with technical assistance from the Public Health Agency of Canada. This SGS was designed to monitor the HIV epidemic among key populations at high risk, that is, PWIDs, and hijra, male and female sex workers (HSWs, MSWs and FSWs, respectively). Since the first pilot SGS was conducted in 2004, Pakistan has conducted four SGS rounds with PWIDs, HSWs, MSWs and FSWs in 8 major cities in 2005-2006, 12 cities in 2006-2007, 9 cities in 2007-2008 and 20 cities in 2011. ${ }^{8-12}$ Findings from these surveys revealed changes in the HIV magnitude and trends over time, which helped in developing a comprehensive response to the epidemic. ${ }^{13-15}$ The approach proved to be extremely relevant in a concentrated epidemic such as Pakistan's, whereby behavioural information is vital in predicting epidemic transition.

This paper shares the key results of the 4th round of SGS conducted in 20 cities in Pakistan. We also present key experiences and lessons learnt in the development of an effective SGS system, which can be utilised within the Asian, Eastern European and Latin American countries, but more importantly be contextually relevant for the Middle East and North Africa (MENA) region, for the development of a response against HIV/AIDS.

\section{METHODOLOGY}

The SGS methodology was divided into two parts: a mapping exercise for size estimation among PWIDs, MSWs, HSWs and FSWs; and Integrated Behavioral and Biological Surveillance (IBBS). Round 4 of the mapping was conducted in 20 
cities (9 in Punjab, 7 in Sind, 2 each in Khyber PukhtoonKhwa and Baluchistan) and round 4 of the IBBS was conducted in all these cities with the exception of Hyderabad, Larkana and Mirpurkhas in Sind. The cities were selected based on population size, reported number of HIV cases and because of their inclusion in the previous rounds for comparison.

\section{Mapping of key populations at a higher risk of HIV}

The first step of field activity was mapping of key populations in targeted cities to obtain a better understanding of population sizes and patterns of risk behaviour. Two different approaches were used: geographical and network mapping. ${ }^{16}$ The geographical approach involved characterising sex work (MSWs, street and brothel-based FSWs) and injection drug use, and estimating the number of individuals involved in these activities through identifying and characterising locations and spots, that is, 'hot spots' where high-risk activities take place. Each city was divided into smaller data collection units referred to as 'zones', with detailed zonal maps for all cities developed using the geographical information system, based on satellite imagery. The information was collected identifying 'hotspots' and places where high-risk activities take place. Field teams went to all identified hotspots to verify the location, describe the type of spot, and get more specific information on the size of the key population (minimum, maximum and median estimates) by interviewing members of key populations operating through that spot. One key population member was interviewed at each spot who provided information of other key population members at that specific spot. Spots not validated, that is, no peer members were found on at least three successive visits, were dropped from the list, while new spots identified or informed by primary key informants were added to the list.

Network mapping focused on the promoters and mediators of sex work; network operators (pimps for FSWs and 'gurus' for HSWs) and mapped networks within which the target populations operate. Network operators were systematically identified within each zone through a process of 'snowballing', whereby each key informant in the field (pimps and gurus) were asked to identify others that they knew. This process continued until a level of 'saturation' was attained (ie, mostly redundant information was provided from the new contacts about other network operators).

All data were field edited and entered into a specially designed Microsoft Access database. The final stage of information consists of data triangulation and developing a city-wide estimate through combining zonal estimates and removing overlaps. To generate final estimates of each risk population, a cumulative estimate for each zone was initially developed by adding up minimum and maximum estimates for each site and location. These estimates were adjusted for duplication and overlaps and finally all zonal estimates were added up to produce minimum and maximum estimates of the population under study for each city. ${ }^{12} 16$

\section{Integrated Behavioural and Biological Survey}

Final mapping estimates were used to design sampling frames from which representative samples of each key population were drawn. Sample sizes were calculated based on an expected change in prevalence of various risk behaviours (condom use in sex workers and needle sharing in PWIDs) by $10 \%$ with $95 \%$ significance level and $80 \%$ power. The sample sizes calculated were: 365 PWIDs, 375 FSWs, 360 MSWs and 356 HSWs for each site. Sampling of each population was conducted based on its dynamics and operative nature. PWIDs and MSWs were recruited through multistage cluster sampling, while HSWs were

recruited using information obtained from network mapping of 'gurus' to gather information on both 'dera-based' and 'homebased' hijras categorised by the way in which they operate and where they dwell. Dera is a house operated under the supervision of a guru (teacher), where a number of his adopted chela's (student hijra) live. Among FSWs, brothel-based FSWs were selected through systematic random sampling, while street-based FSWs (who solicit clients in public places through cruising sites or pick-up points) were selected through multistage cluster sampling. Kothi-khana (FSWs who live in small premises/houses rented by a network operator and entertain clients) and homebased FSWs (sex workers who live at home with their families and are involved in covert sexual activities through contacts with network operators) were recruited through a similar sampling technique used for HSWs after applying sampling weights obtained from the mapping study. Behavioural data were collected by trained interviewers using structured questionnaires predesigned in English and subsequently translated into the local language. Informed consent was obtained prior to conducting the interviews. Dried blood spot (DBS) specimens were collected by trained interviewers. ${ }^{17}{ }^{18}$ All DBS specimens were first screened by ELISA. Positive results were subsequently confirmed in duplicate by the Vironostika HIV Uni-Form II EIA and indeterminate specimens were confirmed by Western blot.

Data entry was conducted by trained staff supervised by a data manager. Laboratory results were linked to the corresponding interview data by the encrypted unique identifier and unique study site code; no personal information accompanied these records. The final dataset was converted to SPSS files (version 19.0) for analysis. The study protocol was reviewed and approved by the Ethical Review Board of the Public Health Agency of Canada, and in Pakistan by HOPE International's Ethical Review Board. HSWs/MSWs received a compensation of Rs 300 (\$4 per person), PWIDs received Rs 250 (\$3 per person) and FSWs received Rs 500 ( $\$ 6$ per person) for their time.

\section{RESULTS}

\section{Operational dynamics and size estimations}

The estimated population sizes in the 20 mapped cities were 89178 FSWs, 46351 PWIDs, 23317 HSWs and 19119 MSWs, as illustrated in table 1. The largest FSW typology were home-based sex workers (average 41313), followed by kothi-khana-based sex workers (average 20 926), street-based

Table 1 Estimates of key populations derived from mapping of 20 cities in Pakistan, 2011-2012

\begin{tabular}{lll}
\hline Key population type & Average (n) & $\%$ \\
\hline Female sex workers (FSWs) & 89178 (78778-99592) & \\
Brothel based & 1268 & 1 \\
Home based & $41313(3.5 /$ NWO $)$ & 46 \\
Street based & $18275(4.6$ per spot) & 21 \\
Kothi khana based & $20926(1.7 /$ NWO $)$ & 24 \\
Cell phone based & 4714 & 5 \\
Other & 2682 & 3 \\
People who inject drugs & $46351(39793-52896)$ & \\
Hijra sex workers & $23317(20050-26634)$ & \\
Dera based & 16433 & 70.5 \\
Home based & 6884 & 29.5 \\
Male sex workers & $19119(16010-22220)$ & \\
\hline NWO, Net Work Operators. & &
\end{tabular}


sex workers (average 18275 ), cell phone based sex workers (average 4714), and finally, brothel-based sex workers (average 1268). An average of 3.5 home-based FSWs in comparison to 1.7 kothi-khana-based FSWs were reported to be working with a network operator, while an average of 4.6 FSWs were attached to each street spot.

The second largest key population was PWIDs (average 46351 ), the majority of which were reported to be injecting on the streets. HSWs were the third largest key population mapped, among which two major subtypes were identified: home based (average 6884) and dera based (average 16 433).

\section{Sociodemographic characteristics}

The key sociodemographic characteristics of PWIDs, MSWs, HSWs and FSWs recruited for this behavioural and biological assessment are shown in table 2. PWIDs were the oldest of the four groups, with an average age of 30.4 years (SD \pm 8 ), while MSWs were the youngest (average age 21.4 years $(S D \pm 5.0)$ ). Unexpectedly, $42 \%$ of MSWs were between the ages of 13 and 19 years, while another $36 \%$ were between the ages of 20 and 25 years. Of all the key populations studied, FSWs represented the largest proportion who reported to be currently married (63.7\%), while only $13 \%$ of HSWs and $15 \%$ of MSWs reported being currently married. Nearly half of PWIDs reported living on the streets. Most HSWs reported living in deras (70.6\%), with their peer group members. A high proportion of FSWs and HSWs were not natives of the city where they were recruited, demonstrating a high level of mobility.

Table 3 shows the various HIV risk behaviours and injecting and sexual practices.

\section{Drug-injecting practices}

PWIDs reported first injecting drugs at an average age of 25.6 years and reported injecting for approximately 4.9 years on average. A total of $39.2 \%$ of PWIDs reported sharing a needle/ syringe during their last injection, while $44.3 \%$ used the services/help of a professional injector during their last injection.

\section{Sexual behaviour}

MSWs and HSWs reported initiating sex work at an average age of 16 years, whereas FSWs reported initiating sex work at an average age of 21.9 years. Duration of being involved in sex work was the highest for HSWs (average 11.6 years), followed by MSWs (average 5.6 years) and FSWs (average 5.3 years). The main source of soliciting clients for the various sex workers also varied. The dependence of FSWs on pimps and network operators for soliciting clients was highest (43.1\%) compared with other sex worker groups, namely MSWs and HSWs. MSWs predominantly solicited clients directly through public places $(57.6 \%)$ and had little or no dependency on any network operators $(0.8 \%)$. A large reliance on cell phones to solicit and set meeting times was reported in all three sex worker groups, with the highest proportion being reported among HSWs (44.4\%), followed by MSWs (30.4\%) and then FSWs (24.7\%). Only $10.7 \%$ of HSWs showed a dependence on a guru for client solicitation. FSWs reported that on days that they worked, they entertained an average of 3.0 ( $\mathrm{SD} \pm 2.3$ ) clients per day, while HSWs and MSWs reported having an average of $2.2(\mathrm{SD} \pm 1.6)$ and 2.3 ( $\mathrm{SD} \pm 1.4$ ) clients per day, respectively. On average, FSWs reported having 50.0 (SD \pm 37.2 ) clients in a month, while HSWs and MSWs reported having an average of 40.0 (SD $\pm 33.0)$ and 40.4 (SD \pm 32.1$)$ clients per month, respectively. One-third of FSWs interviewed reported using condoms consistently with paid clients, while only $13 \%$ of MSWs and $23.6 \%$ of HSWs reported consistent condom use. Condom use was lower when the sexual partner was reported to be a non-paying regular partner. Lubricant use during last anal sex was higher than condom use among HSWs and MSWs at $66.5 \%$ and $71.1 \%$, respectively.

Overlapping among these populations was seen as $13.9 \%$ of PWIDs and $39.5 \%$ of MSWs paid a FSW for sex in the past month, and $7.1 \%$ of PWIDs had sex with either an MSW or an HSW. Furthermore, $10.7 \%$ of FSWs and $10.1 \%$ of HSWs and MSWs reported having had sex with a PWID in the past 6 months. In addition, $4.9 \%$ FSWs, $3.4 \%$ of HSWs and $1.7 \%$ of MSWs reported injecting drugs in the past 6 months.

\section{HIV sero-prevalence}

Table 4 shows the weighted HIV sero-prevalence among all key populations surveyed. The prevalence among PWIDs was the highest among all key populations surveyed at $37.8 \%$ nationally, followed by a national sero-prevalence of $7.2 \%$ among HSWs, $3.1 \%$ among MSWs and $0.8 \%$ nationally for FSWs.

Table 2 Sociodemographic characteristics of people who inject drugs (PWIDs), male sex workers (MSWs), hijra sex workers (HSWs) and female sex workers (FSWs) in Pakistan

\begin{tabular}{|c|c|c|c|c|}
\hline Sociodemographic characteristics & $\begin{array}{l}\text { PWIDs } \\
\mathrm{N}=4956( \pm \text { SD) }\end{array}$ & MSWsN=3674 ( $($ SD) & $\begin{array}{l}\text { HSWs } \\
\mathrm{N}=3714( \pm \mathrm{SD})\end{array}$ & $\begin{array}{l}\text { FSWs } \\
\mathrm{N}=4298( \pm \mathrm{SD})\end{array}$ \\
\hline Average age & $30.4 \pm 8$ & $21.4 \pm 5.0$ & $27.6 \pm 6.2$ & $26.9 \pm 6.4$ \\
\hline Currently married (\%) & 33.8 & 15.5 & 13 & 63.7 \\
\hline Illiterate (\%) & 57.1 & 40.0 & 42.4 & 50.6 \\
\hline \multicolumn{5}{|l|}{ Current living at (\%) } \\
\hline Home & 45.4 & 80.9 & 29.1 & 84.3 \\
\hline Street & 47.6 & - & - & - \\
\hline Dera & - & 3.5 & 70.6 & - \\
\hline Alone & - & 5.1 & - & 5.8 \\
\hline Median income, PKR (\$) & $6000(68)$ & $6000(69)^{*}$ & $7000(77)^{*}$ & $15000 *(165)$ \\
\hline \multicolumn{5}{|l|}{ Migration from other cities (\%) } \\
\hline Permanently staying & 89.5 & 60.3 & 59.3 & 55.6 \\
\hline Visiting & 10.5 & 39.7 & 40.7 & 44.4 \\
\hline
\end{tabular}

Integrated Behavioural and Biological Surveillance, 2011-2012.

*Income from sex work only. 
Table 3 Sexual behaviours and practices of people who inject drugs (PWIDs), male sex workers (MSWs), hijra sex workers (HSWs) and female sex workers (FSWs) in Pakistan

\begin{tabular}{|c|c|c|c|c|}
\hline Practice/behaviour & PWIDs ( \pm SD) & MSWs ( \pm SD) & HSWs ( \pm SD) & FSWs ( $( \pm$ SD) \\
\hline Age of initiating (sex work; injecting) (avg $\pm S D$ ) & $25.6 \pm 8.2$ & $15.8 \pm 3.1$ & $16 \pm 3.6$ & $21.9 \pm 5.6$ \\
\hline Duration (in sex work; as PWIDs) & $4.9 \pm 4.4$ & $5.6 \pm 4.3$ & $11.6 \pm 5.9$ & $5.3 \pm 6.6$ \\
\hline Sharing needle/syringe at last injection & 39.2 & & & \\
\hline Injected by professional injector at last injection & 44.3 & & & \\
\hline \multicolumn{5}{|l|}{ Main source of clients } \\
\hline Pimp/guru/madam & & 0.8 & 10.7 & 43.1 \\
\hline Directly from public places & & 57.6 & 38.0 & 22.3 \\
\hline Cell phone contact & & 30.4 & 44.4 & 24.7 \\
\hline Client referral & & 10.8 & 6.5 & 9.6 \\
\hline Other sources & & 0.3 & 0.3 & \\
\hline \multicolumn{5}{|l|}{ Number of clients } \\
\hline Avg clients/day \pm SD & & $2.3 \pm 1.4$ & $2.2 \pm 1.6$ & $3.0 \pm 2.3$ \\
\hline Avg clients in past month $\pm S D$ & & $40.4 \pm 32.1$ & $40.0 \pm 33.0$ & $50.0 \pm 37.2$ \\
\hline \multicolumn{5}{|l|}{ Consistent condom use with } \\
\hline Paid clients & & 13.0 & 23.6 & 33.2 \\
\hline Non-paid sex partner & & 10.9 & 18.1 & 20.6 \\
\hline Lubricant use during last anal sex & 40.1 & 71.1 & 66.5 & \\
\hline Paid a FSW in the past month & 13.9 & 39.5 & & \\
\hline Had sex with a MSW/HSW & 7.1 & & & \\
\hline Injected drugs in the past 6 months & 100 & 1.7 & 3.4 & 4.9 \\
\hline Had sex with PWIDs in past 6 months & & 10.1 & 10.1 & 10.8 \\
\hline
\end{tabular}

\section{DISCUSSION}

Since it was first detected in 1986, the HIV/AIDS epidemic in Pakistan has progressed from a low-level epidemic to a concentrated epidemic, with measurable prevalence rates among all prominent risk behaviour groups. Pakistan's HIV epidemic, once concentrated primarily among PWIDs, is now increasingly characterised by significant sexual transmission (ie, MSWs, HSWs and FSWs,.). ${ }^{19}$ While many countries in the MENA region are still trying to identify and describe their key populations, Pakistan has already established a knowledge base to characterise, operationalise and estimate the sizes of their key populations. ${ }^{16}$

This study found a large population of PWIDs in Pakistan, much higher than that found in previous studies of PWIDs. ${ }^{9} 10$

Table 4 HIV prevalence among people who inject drug (PWIDs), male sex workers (MSWs), hijra sex workers (HSWs) and female sex workers (FSWs) in Pakistan

\begin{tabular}{|c|c|c|c|c|}
\hline \multirow[b]{2}{*}{ City } & \multicolumn{4}{|c|}{ HIV prevalence, \% $(95 \% \mathrm{CI})$} \\
\hline & PWIDs & MSWs & HSWs & FSWs \\
\hline Overall & 37.8 (37.3 to 38.3$)$ & 3.1 (2.8 to 3.4$)$ & 7.2 (6.8 to 7.5$)$ & $0.8(0.4$ to 1.0$)$ \\
\hline DG Khan & 49.6 (45.6 to 53.6$)$ & NA & NA & $0.5(0.1$ to 1.9$)$ \\
\hline Faisalabad & 52.5 (51.4 to 53.6$)$ & $0.3(0.07$ to 1.5$)$ & $3.9(2.3$ to 6.5$)$ & 0 \\
\hline Gujrat & $46.2(41.5$ to 50.9$)$ & NA & NA & NA \\
\hline Lahore & 30.8 (29.3 to 32.3$)$ & 1.7 (0.8 to 3.6) & 5.2 (3.5 to 8.2 ) & $0.5(0.1$ to 1.9$)$ \\
\hline Multan & 25.0 (22.2 to 28.0 ) & $1.9(0.96$ to 4.0$)$ & $1.1(0.5$ to 2.9$)$ & 0.3 (0.05 to 1.5$)$ \\
\hline Pakpattan & 3.3 (2.1 to 5.3 ) & NA & NA & NA \\
\hline Rahim Yar Khan & 14.9 (11.8 to 18.6$)$ & NA & NA & NA \\
\hline Sargodha & 40.6 (38.2 to 43.0$)$ & 0 & 3.7 (2.2 to 6.2$)$ & 0.3 (0.05 to 1.6$)$ \\
\hline Rawalpindi & NA & $0.6(0.2$ to 2.0$)$ & $4.2(2.6$ to 6.9$)$ & 0 \\
\hline Dadu & 16.0 (13.0 to 19.6) & NA & NA & NA \\
\hline Karachi & 42.2 (41.4 to 42.9$)$ & 5.9 (3.9 to 8.9$)$ & $12.0(9.3$ to 16.1$)$ & $1.9(0.9$ to 3.8$)$ \\
\hline Larkana & 18.6 (16.4 to 21.0$)$ & 3.1 (1.7 to 5.4$)$ & 14.9 (11.6 to 19.1) & $1.9(0.9$ to 3.8$)$ \\
\hline Sukkur & $19.2(17.5$ to 21.0$)$ & $2.2(1.2$ to 4.3$)$ & 6.2 (4.1 to 9.2$)$ & $0.8(0.3$ to 2.3$)$ \\
\hline Haripur & 7.9 (5.8 to 10.3$)$ & 0 & 0 & 0.9 (0.3 to 3.4$)$ \\
\hline Peshawar & 20.0 (18.3 to 21.9$)$ & 0 & $1.1(0.5$ to 2.9$)$ & 0 \\
\hline Quetta & 7.1 (5.3 to 9.3 ) & $1.1(0.5$ to 2.8$)$ & $2.7(1.4$ to 5.1$)$ & 0 \\
\hline Turbat & 21.4 (17.8 to 25.5$)$ & NA & NA & NA \\
\hline
\end{tabular}

Integrated Behavioural and Biological Surveillance, 2011-2012. 
There is an apparent increasing shift from inhalation to injection drug use across the country, which has led to these high numbers. ${ }^{6}$ The results of this study also highlight the presence of a well developed sex work industry, in all large and smallsized cities in Pakistan where mapping data were collected. We saw evidence of diminishing street-based sex work and the presence of much larger hidden networks managed by pimps and network operators. Moreover, improvements in communication technology, especially the availability of cell phones, have revolutionised the sex industry in Pakistan. Sex workers now interact with clients via cell phones, without having to stand on streets to find clients, or involving network operators. ${ }^{9} 1016$

Serial prevalence data obtained from the SGS rounds in Pakistan provide an understanding of the progression of HIV in this country. ${ }^{8-11}$ The sero-prevalence among PWIDs has shown a consistent increase across all rounds, which increased from $10.8 \%$ in 2005 to $37.8 \%$ in 2011 . Although the analysis conducted in 2011 produced a weighted HIV prevalence, and the numbers cannot be strictly compared with the previous rounds (as previous analyses were not weighted), it does show an upward and a rapid progression of HIV prevalence in this group. Likewise among HSWs, the gradual and consistent increase in HIV prevalence from $0.8 \%$ in 2005 to $7.2 \%$ in 2011 indicates that the epidemic is now well established in this group. A similar trend is noted in MSWs, which now stands at an overall HIV sero-prevalence of $3.1 \%$. While only one FSW tested positive for HIV from a sample of 12 cities in 2007, 25 FSWs tested positive for HIV from the same number of cities in this round. ${ }^{10}$ Even with lower prevalence rates, the sheer size of this population and its close links with the general population warrants careful monitoring of this population to ensure successful prevention of HIV transmission.

While looking at HIV risk behaviours, multiple practices known to put PWIDs at a higher risk for acquiring infection were found. These mainly included sharing of needles and using services of professional injectors/street doctors (PWIDs themselves, who assist other PWIDs in injecting). In comparison to previous studies, the number of PWIDs using the service of professional injectors has increased significantly over the years. ${ }^{9} \quad 10$ Since these professional injectors use the same injecting equipment on multiple PWIDs, this explains to some extent why the HIV epidemic among PWIDs has exploded in various cities surveyed in this round.

Sex workers reported to engage in a combination of HIV risk practices such as having a high number of sex partners and engaging in unprotected sex with paying and non-paying partners. Consistent condom use which is the key to preventing sexual transmission of HIV infection showed significantly low levels, most notably in MSWs and HSWs. Given the potential for the spread of HIV infection through unprotected anal sex, the progression of HIV in these populations and their possible role in bridging sexual networks to PWIDs is a cause for serious concern. Service utilisation data from Pakistan continues to show low levels of awareness about, and participation in, prevention programmes. This indicates the need to scale up interventions and bring substantial improvement in coverage to reach a larger proportion of these key populations.

A few limitations of this study should be acknowledged. Regarding results of the mapping, there is a possibility of missing some spots and either overestimating or underestimating some key population groups depending on the extent of their invisibility. Thus, sex workers operating through network operators or cell phones are likely to be under-represented. Moreover, since the methodology relies on numeric estimates rather than a count of population members at a spot, the possibility exists that some key informants may still overestimate or underestimate the numbers, depending on their numeric orientation and competence. Finally since the behavioural assessment asked for a few exposures from the past, there might be issues of recall, especially with PWIDs. Despite these limitations, this research provided appropriate and vital information about the nature and risk practices of the key populations, their transmission dynamics, their networks and sub-typologies. ${ }^{20} 21$ These details are imperative in programme design, ensuring a service delivery package that optimises coverage and penetrates deeply into the population networks is feasible. Pakistan is fortunate in terms of its wealth of scientific data that are to be used to better set priorities and define responses. ${ }^{22}$ There is a need to develop concrete strategic plans for each vulnerable sub-population, initially by focusing prevention resources on those with higher risk or vulnerability, and subsequently, by expanding these prevention efforts outward to reach those with lower risk of HIV.

\section{Key messages}

- Pakistan's HIV epidemic that once was characterised primarily by transmission among people who inject drugs (PWIDs) is now increasingly characterised by significant sexual transmission.

- Despite various preventive efforts, PWIDs continue sharing syringes and unprotected sex is frequent among sex workers, most notably in male sex workers and hijra sex workers.

- The future of the HIV epidemic in Pakistan will depend on the scope and effectiveness of HIV prevention programmes for PWIDs, their sexual partners, sex workers and their clients.

\section{Handling editor Jackie A Cassell}

Acknowledgements The authors would like to acknowldge the entire HASP team, the NGO partners and the government counterparts who made this project a success. Above all they would like to thank all key population members who participated in the study. The authors would also like to acknowledge the support and assistance provided by Laith J Abu-Raddad in finalising this manuscript.

Contributors FE was the PI of the study, led the field data collection, analysis and interpretation of results, and was the lead on the development of this manuscript. MS wrote sections of this manuscript and also conducted a few analyses. NA contributed to the writing of the manuscript and provided feedback on the various analyses. SA wrote sections of this manuscript, conducted a literature search and finalised the references. TER was the lead epidemiologist and data analyst and conducted the data analysis.

Funding The HIVIAIDS surveillance project was funded by the Canadian International Development Agency (CIDA) grant number PK-30849.

Competing interests None.

Ethics approval Public Health Agency of Canada and Hope International's Ethical Review Board.

Provenance and peer review Commissioned; externally peer reviewed.

Open Access This is an Open Access article distributed in accordance with the Creative Commons Attribution Non Commercial (CC BY-NC 3.0) license, which permits others to distribute, remix, adapt, build upon this work non-commercially, and license their derivative works on different terms, provided the original work is properly cited and the use is non-commercial. See: http://creativecommons.org/ licenses/by-nc/3.0/ 


\section{REFERENCES}

1 Wilson D, Halperin DT. 'Know your epidemic, know your response': a useful approach, if we get it right. Lancet 2008;372:423-6.

2 Lazarus JV, Curth N, Bridge J, et al. Know your epidemic, know your response: targeting HIV in Asia. AIDS 2010;24(Suppl 3):S95-9.

3 UNAIDS. Global report: UNAIDS report on the global AIDS epidemic. Geneva: UANIDS; 2010. http://www.unaids.org/documents/20101123_globalreport_em.pdf (accessed 18 Dec 2012).

4 Schito M, Peter TF, Cavanaugh S, et al. Opportunities and challenges for cost-efficient implementation of new point-of-care diagnostics for HIV and tuberculosis. J Infect Dis 2012;205(Suppl 2):S169-80.

5 Emmanuel F, Adrien A, Athar, et al. Using surveillance data for action: lessons learnt from the second generation HIVIAIDS surveillance project in Pakistan. East Mediterr Health J 2011;17:712-18.

6 National AIDS Control Program. HIVIAIDS surveillance project. Mapping Report. Round 4 report: 2011. Islamabad, Pakistan: Ministry of Health, 2011.

7 HIV AIDS Surveillance Project. Project implementation plan. 2002. National AIDS Control Program. Islamabad, Pakistan: Ministry of Health.

8 National AIDS Control Program. Integrated biological and behavioral surveillance. Round 1 report. Islamabad, Pakistan; 2005.

9 National AIDS Control Program. Integrated biological and behavioral surveillance. Round 2 report. Islamabad, Pakistan; 2007.

10 National AIDS Control Program. Integrated biological and behavioral surveillance. Round 3 report. Islamabad, Pakistan; 2008.

11 National AIDS Control Program. Integrated biological and behavioral surveillance. Round 4 report. Islamabad, Pakistan; 2011.
12 National AIDS Control Program. HIVIAIDS surveillance project. Mapping: field operations and monitoring manual. Islamabad, Pakistan; 2008.

13 Brown T, Grassley NC, Garnett G, et al. Improving projections at the country level: the UNAIDS Estimation and Projection Package 2005. Sex Transm Infect 2006;82 (Suppl 3):34-40.

14 Low-Beer D, Sarkar S. Catalyzing HIV prevention in Asia: from individual to population level impact. AIDS 2010;24(Suppl 3):S12-19.

15 Brown T. Behavioral surveillance: current perspectives, and its role in catalyzing action. J Acquir Immune Defic Syndr 2003:32(Suppl 1):S12-17.

16 Emmanuel F, Blanchard JF, Zaheer HA, et al. The HIVIAIDS Surveillance Project mapping approach: an innovative approach for mapping and size estimation for groups at a higher risk of HIV in Pakistan. AIDS 2010;24(Suppl 2):S77-84.

17 Solomon SS, Solomon S, Rodriguez II, et al. Dried blood spots (DBS): a valuable tool for HIV surveillance in developing/tropical countries. Int J of STD and AIDS 2002:13:25-8.

18 De Mulder M, Holguín A. Dried blood spots for monitoring HIV infection in public health programs in developing countries. Enferm Infecc Microbiol Clin 2013;31:100-7.

19 Emmanuel F, Akhtar N, Blanchard JF. The rising epidemic of HIV in Pakistan: challenges to a comprehensive response. In: Narain P, ed. Three decades of HIV/ AIDS in Asia. Sage Publications India Pvt, 2012:124-38.

20 World Health Organization and UNAIDS. Initiating second generation HIV surveillance systems: practical guidelines. Geneva: World Health Organization, 2002.

21 Rehle T, Lazzari S, Dallabetta G, et al. Second-generation HIV surveillance: better data for decision-making. Bull World Health Organ 2004;82:121-7.

22 Graham ID, Logan J, Harrison MB, et al. Lost in knowledge translation: time for a map? J Contin Educ Health Prof 2006;26:13-24. 